\title{
L-dopa and arousal ${ }^{1}$
}

\author{
THOMAS B. HORVATH AND RUSSELL A. MEARES \\ From the Departments of Medicine and Psychiatry, University of Melbourne, \\ Austin Hospital, Heidelberg, Victoria, Australia
}

SYNOPSIS In 10 patients with Parkinsonism, treatment with L-dopa was associated with a rise in the skin conductance level and its fluctuations, an increased electromyographic activity in the frontalis muscle, and with faster reaction times. The change of skin conductance in response to a loud noise also increased and its habituation to the repetition of the stimulus was delayed. One patient developed a schizophreniform psychosis and showed high arousal and absent habituation. It is possible that dopamine is the transmitter associated with the arousal reaction and that it plays a part in the pathogenesis of schizophrenia.

L-dopa has gained an important place in the treatment of Parkinson's disease since its successful use in high dosage by Cotzias et al. (1969). A number of clinicians (Godwin-Austen et al., 1969; Yahr et al., 1969) noticed an 'alerting' or 'arousing' effect of this agent which was not always related to the degree of clinical improvement in the primary symptoms of Parkinson's disease. Psychiatric evaluation revealed an improvement in depressive symptoms among some patients with Parkinsonism, but the administration of L-dopa was effective in the treatment of retarded but not of agitated depression (Bunney et al., 1969; Bunney et al., 1971).

Concurrently, the mental side effects of L-dopa therapy were noted to be irritability, sleeplessness, nervousness, agitation, toxic delirium, hallucinations and, much less frequently, depression (Knopp, 1970). Cases of hypomania and paranoid psychosis were described by O'Brien et al. (1971). Most of these side-effects may be products of increased arousal.

A recent study (Marsh et al., 1971) has reevaluated the psychological effects of L-dopa using 32 patients taking L-dopa compared with matched normal controls on no drug therapy. The methods employed to assess 'alerting' or 'arousal' included tests of short-range memory,

1 This investigation was supported by the N.H. and M.R.C. of Australia. vigilance, attention, concentration, and perception. No physiological methods were used.

The results of this investigation proved to be largely negative and the authors arrived at the conclusion that no significant rise of arousal is produced by L-dopa. However, their methods include variables influenced by many factors apart from arousal. In view of this controversy, it appeared useful to test patients with Parkinson's disease before and during L-dopa administration, using physiological methods that have been shown to have a direct relationship to arousal (Lader and Wing, 1966).

\section{METHODS}

PATIENTS The first 10 patients admitted into a treatment trial of L-dopa in Parkinson's disease were studied. There were six males and four females, and their ages ranged from 50 to 74 years. None had a history of encephalitis and none had prominent cerebrovascular disease or a significant systemic illness. The patients remained on their original dosage of anticholinergic treatment and L-dopa was introduced slowly and increased to a level tolerated by them without nausea or autonomic side-effects. The maximum dose was reached in most cases in two to three months.

Controls were medical or surgical patients without neuropsychiatric disturbances, and they were matched with the patients in terms of age, sex, and their score on Eysenck's Neuroticism factor (Eysenck and Eysenck, 1964).

The patients were clinically examined and were 
also questioned about the occurrence of side-effects. The neurological findings were scored and recorded according to Webster's methods (Webster, 1968). Rigidity, tremor, akinesia, walking, writing, and seborrhoea were the symptom categories, and sideeffects included autonomic, gastrointestinal, and neurological changes.

The physiological methods included the measurement of palmar skin resistance, heart rate and frontalis electromyographic activity during rest and during the presentation of a set of uniform auditory stimuli, followed by the determination of auditory reaction time.

After a full explanation and familiarization with the experimental set-up, the subjects sat in a comfortable armchair in the recording room of the psychophysiology laboratory. Silver-silver chloride electrodes set in plastic cups filled with saline jelly were fixed to their left palm, forearm, forehead, and chest.

The physiological variables were recorded on a Beckman Dynograph. The skin resistance was measured with a 9892A GSR coupler, operating on a Wheatstone principle, the heart rate with a 9857 Cardiotachometer coupler, and the electromyogram (EMG) with a 9852 EMG integrating coupler.

After a 10 minute rest period a series of 20 prerecorded auditory stimuli of $1,000 \mathrm{~Hz}$ frequency and $100 \mathrm{db}$ intensity and $1 \mathrm{~s}$ duration were played on a tape recorder. The stimuli were in the same random order, separated by $30-80 \mathrm{~s}$ of silence, in all instances.

The measurement of the reaction time presents a special difficulty in Parkinson's disease as the delay due to stiffness and akinesia may be added to the delay due to central processing time. It was decided, therefore, to measure reaction time by recording the initial muscle action potentials rather than by utilizing the peak muscle contraction as in switch-closing methods. The stimuli were clicks produced by the output of the stimulator of the 1510A HewlettPackard electr=myograph applied to a loudspeaker and the responses were picked up from surface electrodes applied to the right thenar eminence and displayed on the storage oscilloscope of the EMG. As the sweep of the oscilloscope was triggered by the stimulus, the delay of the motor reaction could be determined with an accuracy of $\pm 1 \mathrm{msec}$. The time of peak motor response was also noted. Twenty stimuli were presented in random order with intervals of 20-80 s.

Tests were carried out before the commencement of L-dopa therapy and then when peak stable dosage was reached, usually after two to three months. Controls (who were not on psychoactive drugs or
L-dopa during this period) were tested after a similar interval.

ANALYSIS OF RESULTS The level of heart rate, electromyogram, and skin resistance were determined at $15 \mathrm{~s}$ intervals during the rest period and the readings were averaged. Skin resistances were transformed to log skin conductances according to convention (Lader and Wing, 1966). Fluctuations of skin conductance greater than $0.0003 \log \mu \Omega$ and the fluctuations of the electromyogram that were greater than twice the baseline were measured during each minute of the rest period and were averaged.

The galvanic skin response to the 20 stimuli was calculated as change in log conductance, and a regression of these values on the log number of stimuli was carried out for each subject on each occasion. Habituation rate was defined as the slope $m$ of the regression line, $\mathrm{y}=\mathrm{b}-\mathrm{mx}$, where the $\mathrm{y}$ coordinate was the $\log$ number of stimuli. The $\log$ habituation point was defined as the log number of stimuli required to extinguish, or habituate, the galvanic skin response.

Reaction times were calculated as the mean and standard deviations of 20 responses.

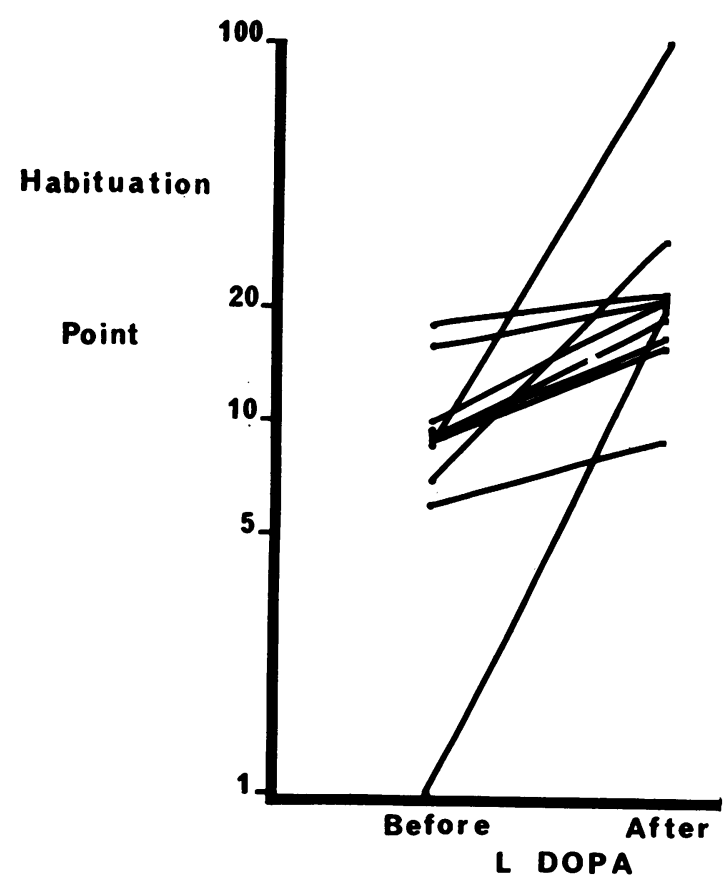

FIG. 1. Habituation point before treatment with L-dopa and after peak dose was reached in 10 Parkinsonism patients. 
TABLE 1

COMPARISON OF 10 PATIENTS WITH PARKINSON'S DISEASE WITH 10 AGE- AND SEX-MATCHED CONTROLS

\begin{tabular}{|c|c|c|c|c|}
\hline & \multicolumn{2}{|c|}{ Controls } & \multicolumn{2}{|c|}{ Parkinsonism } \\
\hline & First occasion & Second occasion & First occasion & Second occasion \\
\hline Dose of L-dopa (g/day) & 0 & 0 & 0 & $5 \cdot 8 \pm 0 \cdot 6^{*}$ \\
\hline Neurological score & 0 & 0 & $10 \cdot 6 \pm 1.9 \ddagger$ & $5 \cdot 4 \pm 1 \cdot 6^{*}$ \\
\hline Side-effect score & 0 & $\mathbf{0}$ & $3 \cdot 3 \pm 0 \cdot 8 \ddagger$ & $4 \cdot 0 \pm 0 \cdot 8^{*}$ \\
\hline First change in log skin conductance ( $u \mathrm{mho})$ & $0.044 \pm 0.017$ & $0.043 \pm 0.013$ & $0.034 \pm 0.013$ & $0.183 \pm 0.052 *$ \\
\hline Habituation rate ( $\mu \mathrm{mho} / \mathrm{stimulus)}$ & $0.047 \pm 0.016$ & $0.051 \pm 0.011$ & $0.036 \pm 0.014$ & $0 \cdot 154 \pm 0.046^{*}$ \\
\hline Log habituation point & $0.814 \pm 0.066$ & $0.762 \pm 0.060 \dagger$ & $0.900 \pm 0 \cdot 100 \ddagger$ & $1 \cdot 300 \pm 0 \cdot 040^{*}$ \\
\hline Log skin conductance level ( $\mu \mathrm{mho})$ & $0.956 \pm 0.122$ & $0.916 \pm 0.121$ & $0.676 \pm 0.136 \pm$ & $1 \cdot 259 \pm 0.111^{*}$ \\
\hline Fluctuations of skin conductance (na/minute) & $2 \cdot 4 \pm 0.6$ & $1 \cdot 9 \pm 0.5 \dagger$ & $3 \cdot 0 \pm 0.8$ & $7 \cdot 1 \pm 0 \cdot 1^{*}$ \\
\hline Frontalis electromyogram $(\mu \mathrm{V})$ & $38 \pm 12$ & $58 \pm 33$ & $40 \pm 13$ & $74 \pm 22^{*}$ \\
\hline Heart rate & $77 \pm 3$ & $80 \pm 5$ & $93 \pm 5+$ & $89 \pm 5$ \\
\hline Systolic blood pressure $(\mathrm{mmHg})$ & $150 \pm 8$ & $147 \pm 8$ & $168 \pm 11 \ddagger$ & $141 \pm 8^{*}$ \\
\hline Reaction time (msec) & $259 \pm 18$ & $273 \pm 30$ & $266 \pm 18$ & $194 \pm 13^{*}$ \\
\hline
\end{tabular}

* Significant $(P<0.05)$ difference between Parkinsonism patients before and after $\mathrm{L}$-dopa.

$\dagger$ Significant $(P<0.05)$ difference between first and second control study.

$\ddagger$ Significant $(\mathrm{P}<0.05)$ difference between controls and Parkinsonism patients before L-dopa.

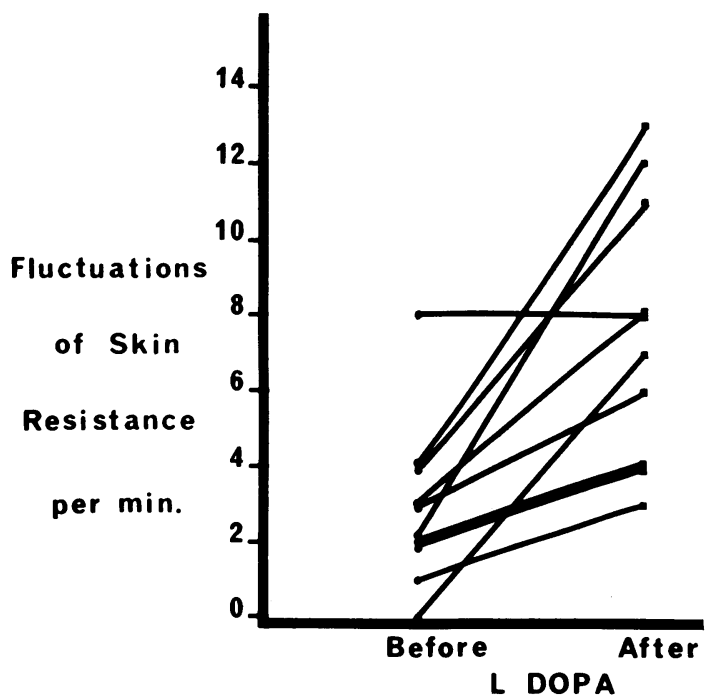

FIG. 2. Fluctuations of skin resistance before treatment with $L$-dopa and after peak dose was reached in 10 Parkinsonism patients.

\section{RESULTS}

There are few significant differences between patients with Parkinsonism and normal control subjects, tested on the first occasion (Table 1). Associated with treatment of Parkinsonism patients with L-dopa, the most prominent changes are in the log habituation point, in the habituation rate, in the size of the first orienting response, in the number of fluctuations of skinconductance per minute, and in the level of skin conductance, in the EMG level, and in the reaction times. This is further demonstrated in Fig. 1 and 2. All these changes are in the direction of increased 'arousal' (Lader and Wing, 1966). Control subjects not receiving L-dopa did not change on re-testing.

Correlation coefficients were also calculated between the dose of L-dopa, the change in clinical manifestations, and the changes in the autonomic indices of arousal (Table 2). The dose

TABLE 2

CORRELATIONS BETWEEN THE DOSE OF L-DOPA AND THE CHANGE IN PHYSIOLOGICAL AND CLINICAL PARAMETERS IN 10 PATIENTS WITH PARKINSON'S DISEASE

\begin{tabular}{|c|c|c|c|c|c|c|c|}
\hline & \multicolumn{7}{|c|}{ Correlation matrix } \\
\hline & $I$ & 2 & 3 & 4 & 5 & 6 & 7 \\
\hline 1. Dose of L-dopa & 1 & & & & & & \\
\hline 2. Change in skin conductance level & $-0 \cdot 218$ & 1 & & & & & \\
\hline 3. Change in habituation point & $0 \cdot 070$ & $0 \cdot 104$ & 1 & & & & \\
\hline 4. Change in fluctuations & -0.051 & $0 \cdot 164$ & 0.879 & 1 & & & \\
\hline 5. Change in orienting reflex & 0.421 & $-0 \cdot 794$ & $-0 \cdot 560$ & $-0 \cdot 604$ & 1 & & \\
\hline 6. Change in habituation rate & 0.547 & -0.605 & -0.644 & -0.656 & 0.951 & 1 & \\
\hline 7. Change in neurological scores & $-0 \cdot 210$ & $0 \cdot 250$ & 0.090 & $0 \cdot 150$ & -0.754 & -0.651 & 1 \\
\hline
\end{tabular}


of L-dopa was not related to the extent of clinical improvement. Nor was it related to the change in measures of baseline arousal-that is, in skin conductance level and its fluctuations. It was, however, positively related to a measure of phasic excitation (the orienting reflex as change in log skin conductance) and its inhibition (the habituation rate). A surprising finding was the negative correlation between the change in clinical scores and the changes in the orienting reflex and its habituation rate.

\section{DISCUSSION}

Duffy (1941) introduced the concept of activation to account for a general factor underlying all the various drives and to account for the reactivity of the animal to environmental stimuli.

This vague psychological construct has been given neurophysiological substance since the demonstration of the function of the brain-stem and thalamic reticular formation by Moruzzi and Magoun (1949) and the application of this to psychology by Lindsley (1951) and Hebb (1955). An increased state of arousal is associated with a desynchronized electroencephalogram (EEG) (Lindsley, 1962), increased heart rate, increased muscle tension, increased palmar sweat gland activity (Lader and Wing, 1966), delayed habituation of the orienting response (block of alpha activity in EEG or a change in skin conductance), and increased responsiveness to stimuli (Sokolov, 1960).

The responsiveness of the individual can be measured by determination of the reaction time, which varies consistently with the level of arousal (Lansing et al., 1959).

This study demonstrates a regular and significant rise in the level of arousal of patients suffering from Parkinson's disease during L-dopa therapy. This is consistent with findings in the rat and rabbit, in which changes in EEG and in motor activity indicated a central arousing effect of L-dopa (Hornykiewicz, 1966).

The arousal effect one expects to be mediated through the ascending reticular formation. Schildkraut and Kety (1967) regarded adrenaline or noradrenaline as the transmitters associated with the arousal reaction. This idea was based on the effect of peripheral injections of these agents and the presence of noradrenaline in brain-stem structures. Intraventricular injections of noradrenaline are sedative, however (Feldberg and Sherwood, 1954), and adrenaline and noradrenaline do not pass the blood-brain barrier in significant amounts (Rothballer, 1959).

Jouvet (1967) showed that behavioural arousal depends on the posterior hypothalamus while cortical arousal depends on cells in the neighbouring mesencephalic tegmentum. He observed that dopa induced a waking state in cats. He also presented evidence which suggested that adrenergic neurones from the pontine reticular formation seemed to be responsible for 'paradoxical' sleep, and serotonergic neurones from the raphe system, for slow wave sleep.

It seems that the administration of L-dopa increases turnover of catecholamines (Schildkraut, 1965), increases dopamine stores (Hornykiewicz, 1966), and reduces the indole amines (serotonin) as well (Bloom and Giarman, 1968), while it hardly affects noradrenaline levels (Everett and Borcherding, 1970).

The site of action affecting symptoms of Parkinsonism is clearly demonstrated to be in the basal ganglia (Hornykiewicz, 1966) through the nigrostriatal tract. This tract may not necessarily be involved in the mediation of arousal. Ungerstedt (1971) has shown that, apart from the classical nigrostriatal dopamine tract, there is the tubero-infundibular dopamine system (concerned with trophic hormone release from the pituitary), and the mesolimbic dopamine system. The latter has cell bodies dorsal to the interpeduncular nucleus in the mid brain and sends fibres to the nucleus accombens and the olfactory tubercle. The mesolimbic system may well play a part in modulating arousal, with dopamine as its transmitter. Before attributing the changes in arousal of our patients to a pharmacological effect of L-dopa, three objections have to be answered.

The first of these concerns the possibility that increased alertness may be a function of improvement in physical well-being. There was, however, no relationship between the degree of improvement in the manifestations of Parkinson's disease and the alteration in baseline arousal. Secondly, it could be suggested that, in at least some of the cases, the initial low arousal levels may have been a function of depression since retarded depression is associated with abnormally 
low levels of arousal (Lader and Wing, 1969). If this were so, then the change in arousal may have been due to an antidepressant effect of L-dopa. This effect is particularly associated with retarded depression (Bunney et al., 1971). None of these cases, however, showed the features of depression before treatment with L-dopa.

Finally, the lack of relationship between the dose of L-dopa and either the change in baseline arousal or the degree of neurological improvement, must be considered. This might be explained in terms of the metabolism of L-dopa, the larger fraction of which is metabolized peripherally. Hinterberger (1971) found that the degree of improvement was related to the level of homovanillic acid in cerebrospinal fluid, but not to urinary or blood metabolites.

A final observation concerns the possible relationship between schizophrenia and the metabolism of dopamine. This is suggested by the clinical observation that antipsychotic drugs commonly induce Parkinsonism. Furthermore, some evidence suggests that certain types of schizophrenia are characterized by high arousal (Venables, 1967), and also by failure of habituation (Meares and Horvath, 1973). Phenothiazines and butyrophenones regularly reduce arousal. It is suggested that they act by blocking dopamine, since the stereoisomeric configuration of chlorpromazine and dopamine show close similarity (Snyder, 1972). Also, the dopamine receptor blocking activity of these preparations is greater than their noradrenaline blocking effect (Andén et al., 1970). In addition, isolated clinical reports (Barbeau, 1969; O'Brien et al., 1971; Celesia and Barr, 1970), suggest that administration of $\mathrm{L}$ dopa may infrequently induce paranoid psychosis. We have also observed a transient paranoid psychosis produced by L-dopa overdosage which was associated with a thought disorder reminiscent of schizophrenia. Physiological recordings showed the high arousal and failure of habituation characteristic of thought disordered schizophrenia (Meares and Horvath, 1973). Also, Barbeau (1971) has noted that a disturbance in directed attention is a consequence of the long-term use of L-dopa, a disorder which may be analogous to the failure of selective inattention found in schizophrenics (Chapman and McGhie, 1962). Finally, bizarre social behaviour, showing similarities with the behaviour of catatonic schizophrenics, has been produced in rats by the combined presentation of a peripheral decarboxylase inhibitor and L-dopa (Lammers and Van Rossum, 1968).

As a consequence of these observations, further investigations are being made into the possible role of the dopaminergic system in arousal, and in the aetiology of schizophrenia.

We thank Dr. P. Bladin, neurologist, Austin Hospital, for allowing us access to his patients, and Roche Products for supplying Levodopa.

\section{REFERENCES}

Andén, N. E., Butcher, S. G., Fuxe, K., Corrodi, H., and Ungerstedt, U. (1970). Receptor activity and turnover of dopamine and noradrenaline after neuroleptics. European Journal of Pharmacology, 11, 303-314.

Barbeau, A. (1971). Long-term side-effects of levo dopa. Lancet, 1, 395.

Barbeau, A. (1969). L-dopa therapy in Parkinson's disease: a critical review of nine years' experience. Canadian Medical Association Journal, 101, 791-800.

Bertler, $\AA$., and Rosengren, E. (1959). Occurrence and $\overline{0}$ distribution of catechol amines in brain. Acta Physiologica Scandinavica, 47, 350-361.

Bloom, F. E., and Giarman, N. J. (1968). Physiologic and pharmacologic considerations of biogenic amines in the nervous system. Annual Review of Pharmacology, 8, 229258.

Bunney, W. E., Jr., Brodie, H. K. H., Murphy, D. L., ando Goodwin, F. K. (1971). Studies of alpha-methyl-paratyrosine, L-dopa, and L-tryptophan in depression and mania. American Journal of Psychiatry, 127, 872-881.

Bunney, W. E., Janowsky, D. S., Goodwin, F. K., Davis, J. M., Brodie, H. K. H., Murphy, D. L., and Chase, T. N. (1969). Effect of L-dopa on depression. Lancet, 1, 885-886.

Butcher, L. L., and Engel, J. (1969). Behavioral and biochemical effects of L-dopa after peripheral decarboxylase inhibition. Brain Research, 15, 233-242.

Celesia, G. G., and Barr, A. N. (1970). Psychosis and other psychiatric manifestations of levodopa therapy. Archives of Neurology (Chicago), 23, 193-200.

Chapman, J., and McGhie, A. (1962). A comparative study of disordered attention in schizophrenia. Journal of Mental Science, 108, 487-500.

Cotzias, G. C., Papavasiliou, P. S., and Gellene, R. (1969). Modification of Parkinsonism - chronic treatment with L-dopa. New England Journal of Medicine, 280, 337-345.

Duffy, E. (1941). An explanation of 'emotional' phenomena without the use of the concept 'emotion'. Journal of General Psychology, 25, 283-293.

Everett, G. M., and Borcherding, J. W. (1970). L-dopa: effect on concentrations of dopamine, norepinephrine, and serotonin in brains of mice. Science, 168, 849-850.

Eysenck, H. J., and Eysenck, S. B. G. (1964). Manual of the Eysenck Personality Inventory. University of London Press: London.

Feldberg, W., and Sherwood, S. L. (1954). Injections of drugs into the lateral ventricle of the cat. Journal of Physiology, 123, 148-167.

Godwin-Austen, T. B., Tomlinson, E. B., Frears, C. C., and Kok, H. W. L. (1969). Effects of L-dopa in Parkinson's disease. Lancet, 2, 165-168. 
Hebb, D. O. (1955). Drives and the C.N.S. (conceptual nervous system). Psychological Review, 62, 243-254.

Hinterberger, H. (1971). The biochemistry of catecholamines in relation to Parkinson's disease. In Symposium on Parkinson's Disease, Sydney, 1970. Australian and New Zealand Journal of Medicine, 1, Suppl. 1, 14-18.

Hornykiewicz, O. (1966). Dopamine (3-hydroxytyramine) and brain function. Pharmacological Reviews, 18, 925-964.

Jouvet, M. (1967). Neurophysiology of the states of sleep. Physiological Reviews, 47, 117-177.

Knopp, W. (1970). Psychiatric changes in patients treated with levodopa. I. The clinical experiment. Neurology (Minneap.), 20, 23-30.

Lader, M. H., and Wing, L. (1966). Physiological Measures, Sedative Drugs and Morbid Anxiety. Maudsley Monograph, No. 14. Oxford University Press: London.

Lader, M. H., and Wing, L. (1969). Physiological measures in agitated and retarded depressed patients. Journal of Psychiatric Research, 7, 89-100.

Lammers, A. J. J. C., and Rossum, J. M. van (1968). Bizarre social behaviour in rats induced by a combination of a peripheral decarboxylase inhibitor and DOPA. European Journal of Pharmacology, 5, 103-106.

Lansing, R. W., Schwartz, E., and Lindsley, D. B. (1959). Reaction time and EEG activation under alerted and nonalerted conditions. Journal of Experimental Psychology, 58, $1-7$.

Lindsley, D. B. (1951). Emotion. In Handbook of Experimental Psychology, pp. 473-516. Edited by S. S. Stevens. Wiley: New York.

Lindsley, D. B. (1952). Psychological phenomena and the electroencephalogram. Electroencephalography and Clinical Neurophysiology, 4, 443-456.

Lynn, R. (1966). Attention, Arousal and the Orientation Reaction. Pergamon Press: Oxford.

Marsh, G. G., Markham, C. M., and Ansel, R. (1971). Levodopa's awakening effect on patients with Parkinsonism. Journal of Neurology, Neurosurgery, and Psychiatry, 34, 209-218.

Meares, R., and Horvath, T. (1973). Physiological differences between hallucinosis and schizophrenia. British Journal of Psychiatry, 122, 687-688.

Mindham, R. H. S. (1970). Psychiatric symptoms in Parkin- sonism. Journal of Neurology, Neurosurgery, and Psvchiatry, 33, 188-191.

Moruzzi, G., and Magoun, H. W. (1949). Brain stem reticular formation and activation of the EEG. Electroencephalography and Clinical Neurophysiology, 1, 455-473.

O'Brien, C. P., DiGiacomo, J. N., Fahn, S., and Schwarz, G. A. (1971). Mental effects of high-dosage levodopa. Archives of General Psychiatry, 24, 61-64.

Rothballer, A. B. (1959). The effects of catecholamines on the central nervous system. Pharmacological Revien's, 11, 494-547.

Scheckel, C. L., Boff, E., and Pazery, L. M. (1969). Hyperactive states related to the metabolism of norepinephrine and similar biochemicals. Annals of the New York Academy of Sciences, 159, 939-958.

Schildkraut, J. J. (1965). The catecholamine hypothesis of affective disorders: A review of supporting evidence. American Journal of Psychiatry, 122, 509-522.

Schildkraut, J. J., and Kety, S. S. (1967). Biogenic amines and emotion. Science, 156, 21-30.

Snyder, S. H. (1972). Catecholamines in the brain as niediators of amphetamine psychosis. Archives of General Psychiatry, 27, 169-179.

Sokolov, E. N. (1960). Neuronal models and the orienting reflex. In The Central Nervous System and Behavior, pp. 187-276. Edited by M. A. B. Brazier. Josiah Macy, Jr. Foundation: New York.

Ungerstedt, U. (1971). Stereotaxic mapping of the monoamine pathways in the rat brain. Acta Physiologica Scandinavica, 367, Suppl. 1-48.

Venables, P. H. (1967). Partial failure of cortical-subcortical integration as a factor underlying schizophrenic behaviour. In The Origins of Schizophrenia, pp. 42-53. International Congress Series No. 151. Edited by J. Romano. Excerpta Medica: Amsterdam.

Warburton, J. W. (1967). Memory disturbance and the Parkinson syndrome. British Journal of Medical Psychology, 40, 169-171.

Webster, D. D. (1968). Critical analysis of the disability in Parkinson's disease. Modern Treatment, 5, 257-282.

Yahr, M. D., Duvoisin, R. C., Schear, M. J., Barrett, R. E., and Hoehn, M. M. (1969). Treatment of parkinsonism with Levodopa. Archives of Neurology, 21, 343-354. 